\title{
Os medicamentos e tecnologias farmacêuticas como uma questão estratégica para a viabilidade do Sistema Único de Saúde
}

\section{| 1 Jorge Bermudez |}

${ }^{1}$ Escola Nacional de Saúde Pública Sergio Arouca, Fundação Oswaldo Cruz. Rio de Janeiro-RJ, Brasil (jorge.bermudez@fiocruz.br). ORCID: 0000-0002-8109-5819.

Recebido em: 16/11/2017

Aprovado em: 13/01/2018

Revisado em: 28/02/2018

DOI: http://dx.doi.org/10.1590/S0103-73312018280102

Uma publicação como esta, um número temático deste porte, é mais do que necessário e esperado nos tempos de hoje. As iniciativas governamentais que vemos atualmente em curso levam a um desmonte de todas as conquistas sociais dos últimos anos. Próximo a completar trinta anos, nosso Sistema Único de Saúde (SUS) vem sendo fragilizado, e campanhas na grande mídia apontam para fragilizá-lo ainda mais e a desmerecer sua importância e impacto na melhoria das condiçóes de saúde e de vida das nossas populações. Nossa Constituição de 1988 está sendo violentada no cotidiano. $\mathrm{O}$ acesso a medicamentos e tecnologias em saúde não poderia estar fora desse redemoinho.

Aprendemos recentemente que a questão do acesso a tecnologias em saúde não pode mais ser considerado apenas um problema para os países em desenvolvimento. Com novos medicamentos, como os antivirais de ação direta para a hepatite $\mathrm{C}$ ou os novos produtos oncológicos, os custos e preços de medicamentos acabam impactando e colocando em risco mesmo os sistemas de saúde privados e os países desenvolvidos (UN, 2016; BERMUDEZ et al., 2016).

Como muito bem nos descreve o Editorial, nossa dependência tecnológica e a destruição do nosso parque farmoquímico, no início da década de 90, nos sujeitam à voracidade da indústria farmacêutica de capital transnacional, aliada às barreiras ao acesso representadas pela proteção monopólica das patentes que nossa Lei de 
Propriedade Industrial permite. Mesmo iniciativas estratégicas, como a rede própria da Farmácia Popular, estáo sendo inviabilizadas, e esta última foi arbitrariamente desativada pelo Ministério da Saúde, apontando para a descentralização de uma parcela mínima de recursos complementares à assistência farmacêutica, o que nitidamente nos coloca a diretriz de privatização também no comércio farmacêutico. A apropriação de iniciativas sociais por interesses comerciais, o lucro desmedido e sem limites e o confronto entre a saúde e o comércio agravam o crônico subfinanciamento do nosso SUS, gerando impacto negativo e políticas recessivas com perda de direitos e muito longe da visão da saúde como direito de todos e dever do Estado que nossa Constituição estabeleceu (BERMUDEZ, 2017a).

Percorrendo os artigos que compóem este número temático, ressaltamos a larga experiência profissional e o compromisso político de todos os autores, aliados à diversidade de vivência e atuação na construção e manutenção de nosso SUS. Os desafios da sustentabilidade da assistência farmacêutica frente aos custos crescentes dos gastos públicos e a adoção do patenteamento no setor farmacêutico são muito bem discutidos, focalizando as estratégias para a reduçáo dos preços de medicamentos, incluindo a produção local, ao mesmo tempo que aprofunda um estudo de caso de medicamento objeto de inclusão em nossa política industrial em saúde.

O litígio e a luta acirrada entre a sociedade civil defendendo os direitos da população e a indústria defendendo direitos comerciais, exclusividade no monopólio oriundo de proteção patentária, embora desvinculada de pesquisa, também são muito bem retratados em torno de vários produtos lançados no mercado recentemente. A luta por transformar produtos monopólicos em domínio público e o papel da incorporação de tecnologias no SUS nos colocam frente ao diálogo de políticas públicas, ativismo e produção acadêmica.

Em outro artigo, diversas fontes oficiais de informaçáo nos remetem a levantamento sobre a evolução da indústria farmacêutica brasileira, suas repercussôes na balança comercial e a avaliação da nossa política industrial em suas conexóes com a conjuntura internacional e o sistema capitalista.

O componente privado do Programa Farmácia Popular do Brasil implantado a partir de 2006 e que conta com a participação marcante do comércio varejista é analisado no que se refere aos gastos com pagamentos de medicamentos, inclusive comparando os gastos entre a transferência de recursos aos municípios e o pagamento no comércio varejista de medicamentos em sistema de copagamento. 
A produção de testes de diagnóstico in vitro para HIV e hepatites virais, a dependência tecnológica, o impacto das importaçôes, a aquisição de conhecimentos e tecnologia, propostas para a produção local, são discutidos com propriedade, buscando a sustentabilidade de programas do SUS e o fortalecimento da nossa capacidade produtiva nacional.

Finalmente, a coleta de informações em 15 municípios do Mato Grosso do Sul, de pequeno porte em sua maioria e considerados prioritários no Plano Brasil sem Miséria, novamente nos coloca frente ao componente privado do Programa Farmácia Popular do Brasil quanto ao aporte de medicamentos. A participação desse programa na assistência farmacêutica nesses municípios foi objeto de análise no artigo.

Para enfrentar a crise econômica e reverter o desmonte do SUS, tanto a produção de tecnologias em saúde como o acesso assegurado da população nos colocam frente a uma questão de direitos humanos fundamentais e ao confronto entre saúde e comércio. Diversas publicações e reflexões recentes nos apontam questóes específicas e caminhos para garantir políticas includentes e benefícios para nossas populaçóes. Fica muito claro que temos que abordar simultaneamente as questôes das políticas farmacêuticas globais, as questóes relacionadas com a produção de insumos, a assistência farmacêutica com todo seu campo de atuaçáo e o desenvolvimento de nosso complexo econômico e industrial da saúde (ABBOTT, DUKES, 2009; OSORIO-DE-CASTRO, 2014; VILLARDI et al., 2017; HASENCLEVER et al., 2016; GADELHA et al., 2017; ABIA, 2017).

Considero necessário ressaltar a importância do Painel de Alto Nível em acesso a medicamentos estabelecido pelo Secretário-Geral das Naçôes Unidas, cujo relatório foi tornado público em setembro de 2016 (UN, 2016). O mandato estabelecido, de "revisar e avaliar propostas e recomendar soluçóes para remediar a incoerência política entre os direitos justificáveis dos inventores, as leis internacionais de direitos humanos, regras de comércio e saúde pública no contexto de tecnologias em saúde”, deixou claro que a questão do acesso a medicamentos hoje é um problema global para todos os sistemas de saúde. Por outro lado, a apropriação desse tema pelo Secretário-Geral das Nações Unidas mostra a importância estratégica do mesmo.

Aprendemos muito com as lições da produção genérica de medicamentos para HIV/Aids. A entrada no mercado das versôes genéricas dos medicamentos nos possibilita que hoje estejam 18,2 milhóes de pessoas em tratamento no mundo, 
sendo que os produtos se encontram a preços acessíveis. Hoje, a saúde ocupa lugar central na Agenda 2030 ou Objetivos de Desenvolvimento Sustentável, e foi nesse contexto, dois meses depois da adoção da Agenda 2030, que o Secretário-Geral das Naçôes Unidas estabeleceu o Painel de Alto Nível mencionado, que gerou o relatório ao final de um período de dez meses de trabalho, reunióes, audiências públicas e consultas. Cabe também destacar que pouco tempo depois se encerraram os trabalhos de outro painel de alto nível, a Comissão Lancet de Medicamentos Essenciais (WIRTZ et al., 2017).

Se efetivamente queremos assegurar o acesso a tecnologias em saúde, temos que enfrentar as barreiras que se encontram apontadas nos dois relatórios mencionados e transformar as recomendaçôes, após análise crítica, em planos de ação, identificando medidas a curto, médio e longo prazos. Insuficiência de inovação, investimentos inadequados, a crise da resistência antimicrobiana devem gerar respostas institucionais fortes, eliminando barreiras como a propriedade intelectual, que evita a competição genérica e prorroga os preços monopólicos, portanto bloqueando o acesso. Uma série de comentários e propostas concretas foram acrescentadas por nós no decurso dos trabalhos do Painel de Alto Nível, como Nota em Separado e constante no relatório. Entretanto, também explicitamos diversas consideraçóes após a divulgação do relatório (BERMUDEZ, 2017a; 2017b).

Finalmente, consideramos que se efetivamente vamos pensar nos medicamentos e tecnologias como uma questão estratégica para a viabilidade do SUS, temos que formular alternativas estratégicas para enfrentar o desmonte hoje em curso. Direitos humanos fundamentais estão em risco. O papel protagônico do Brasil nas questôes relacionadas com o direito à saúde e o acesso universal deve ser enfatizado, e a construção de um sistema que gere equidade e universalidade com controle social tem que ser recuperada, discutida e amplamente implementada para legar um futuro melhor, mais justo e mais estável.

\section{Referências}

ABBOTT, F.M.; DUKES, G. Global pharmaceutical policy. Ensuring medicines for tomorrow's world. Cheltenham, UK: Edward Elger Publishing, 2009.

ASSOCIAÇÃO BRASILEIRA INTERDISCIPLINAR DE AIDS. As politicas de acesso a medicamentos e os direitos humanos no Brasil e no mundo. Rio de Janeiro: ABIA, 2017. 
BERMUDEZ, J.A.Z. Acesso a medicamentos: impasse entre a saúde e o comércio. Cad. Saúde Pública, v. 33, n. 9, p. e00123117, 2017a.

Contemporary challenges on access to medicines: beyond the UNSG High-Level Panel. Ciência \& Saúde Coletiva, v. 22, n. 8, p. 2435-2439, 2017 b.

BERMUDEZ, J.A.Z. et al. Novos medicamentos: quem poderá pagar? Cad. Saúde Pública, v. 32, supl. 2, p. S59-S61, 2016.

GADELHA, C.A.G. et al. (Org.). Brasil Saúde Amanhãa: complexo econômico-industrial da saúde. Rio de Janeiro: Editora Fiocruz, 2017.

HASENCLEVER, L. et al. (Org.). Desafios de operação e desenvolvimento do complexo industrial da saúde. Rio de Janeiro: E-papers Serviços Editoriais, 2016.

OSORIO-DE-CASTRO, C.G.S. et al. Assistência Farmacêutica. Gestão e prática para profissionais de saúde. Rio de Janeiro: Editora Fiocruz, 2014.

UNITED NATIONS. Report of the United Nations Secretary-General's High-Level Panel on Access to Medicines. Promoting innovation and access to health technologies. New York: United Nations Development Programme, 2016.

VILLARDI, P.; FONSECA, F.; SCOPEL, C. (Org.). Políticas de produção local de medicamentos no Brasil: elementos para o debate. Rio de Janeiro: ABIA, 2017.

WIRTZ, V.J. et al. Essential medicines for universal health coverage. Lancet, v.389, p. 403$76,2017$. 